\title{
Synthesis of Highly Soluble and Oxidatively Stable
}

\section{Tetraceno[2,3-b]thiophenes and Pentacenes}

\author{
Sujeewa S. Palayangoda, Rajib Mondal, Bipin K. Shah, Douglas C. Neckers* \\ Center for Photochemical Sciences, Bowling Green State University \\ Bowling Green, OH 43403
}

\section{Supplementary Information}

Contents

Experimental details of 13 and isomeric mixture of 11 and 14

Figure S1. Thin film absorption of 1-6

Figure S2. Cyclic voltammograms of 1-6

Figure S3. Fluorescence spectra of 1-6 in different solvents

Table S1. $\Phi_{F}$ values of 1-6 recorded in different solvents

Figure S4-S14. NMR spectra of 1-6 and 11-14
Page

S2

S3

S3

S4

S4

S5-S14 


\section{Synthesis.}

6,11-Dihydroxy-5,12-tetracenequinone[2,3-b]thiophene (13). Compound 9 (1.72 g, 7 mmol) was mixed with 2,3-thiophenedicarboxaldehyde (1g, $7 \mathrm{mmol})$ in ethanol $(250 \mathrm{ml})$. While stirring 5\% KOH $(10 \mathrm{ml})$ was added and the mixture refluxed for about 12 hours. After the completion of the reaction, the reaction mixture was cooled. Dark brown precipitate was collected by vacuum filtration. This precipitate was washed several times with $\mathrm{EtOH}$. Dichloromethane was used as the eluent for the column chromatography. Yield: $75 \% ;{ }^{1} \mathrm{H}$ NMR $\left(300 \mathrm{MHz} \mathrm{CDCl}_{3}\right) \delta=9.05(\mathrm{~s}, 1 \mathrm{H}), 8.95(\mathrm{~s}, 1 \mathrm{H}), 8.55(\mathrm{~m}, 2 \mathrm{H})$, $7.85(\mathrm{~m}, 3 \mathrm{H}), 7.65(\mathrm{~d}, 1 \mathrm{H}), 3.60$ (broad, $2 \mathrm{H})$. HRMS m/z $[\mathrm{M}]^{+}$calcd for $\mathrm{C}_{20} \mathrm{H}_{10} \mathrm{O}_{4} \mathrm{~S}$ 346.0299, found 346.0294.

\section{6,11-Dimethoxy-5,12-tetracenequinone[2,3-b]thiophene (11) \& 5,12-dimethoxy-} 6,11-tetracenequinone[2,3-b]thiophene (14) (isomeric products). Compound 13 (500 $\mathrm{mg}, 1.4 \mathrm{mmol}$ ) was added to a $500 \mathrm{ml}$ oven dried round-bottom flask equipped with a stir bar and acetone $(100 \mathrm{ml})$ and dioxane $(50 \mathrm{ml})$ were added. While stirring dimethyl sulfate $(2.38 \mathrm{ml}, 14.3 \mathrm{mmol})$ and anhydrous potassium carbonate $(2.39 \mathrm{~g}, 18.8 \mathrm{mmol})$ were also added. The whole mixture was stirred under argon and then refluxed for 36 hours whereupon an orange yellow precipitate formed. This reaction mixture was poured into ice cold water bath to complete the precipitation and filtered. This solid product was washed with cold water several times and then dried in vacuum oven. The solid product turned out to be an isomeric mixture of $\mathbf{1 1}$ and 14, which were separated by an extremely long hour column using dichloromethane as the eluent. 11: ${ }^{1} \mathrm{H} \mathrm{NMR}\left(300 \mathrm{MHz}, \mathrm{CDCl}_{3}\right) \delta$ $=8.84(\mathrm{~s}, 1 \mathrm{H}), 8.75(\mathrm{~s}, 1 \mathrm{H}), 8.45(\mathrm{~m}, 2 \mathrm{H}), 7.77(\mathrm{~m}, 3 \mathrm{H}), 7.60(\mathrm{~d}, 1 \mathrm{H}), 4.18(\mathrm{~s}, 6 \mathrm{H}) .14:{ }^{1} \mathrm{H}$ 
NMR (300 MHz, $\left.\mathrm{CDCl}_{3}\right) \delta=9.00(\mathrm{~s}, 1 \mathrm{H}), 8.92(\mathrm{~s}, 1 \mathrm{H}), 8.32(\mathrm{~m}, 2 \mathrm{H}), 7.75(\mathrm{~m}, 3 \mathrm{H}), 7.61$

(d, 1H), $4.21(\mathrm{~s}, 6 \mathrm{H})$.

Figure S1. Thin film absorption spectra of 1-6

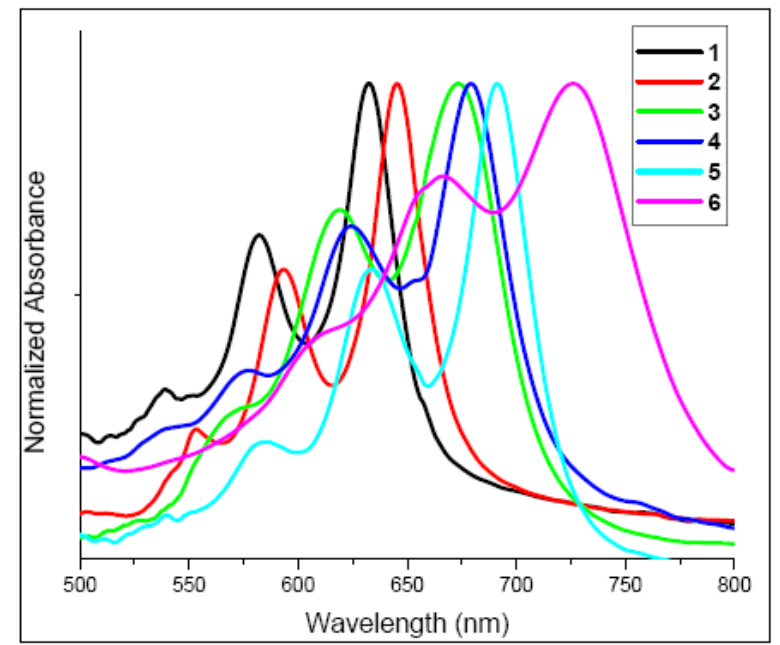

Figure S2. Cyclic Voltammograms of 1-6
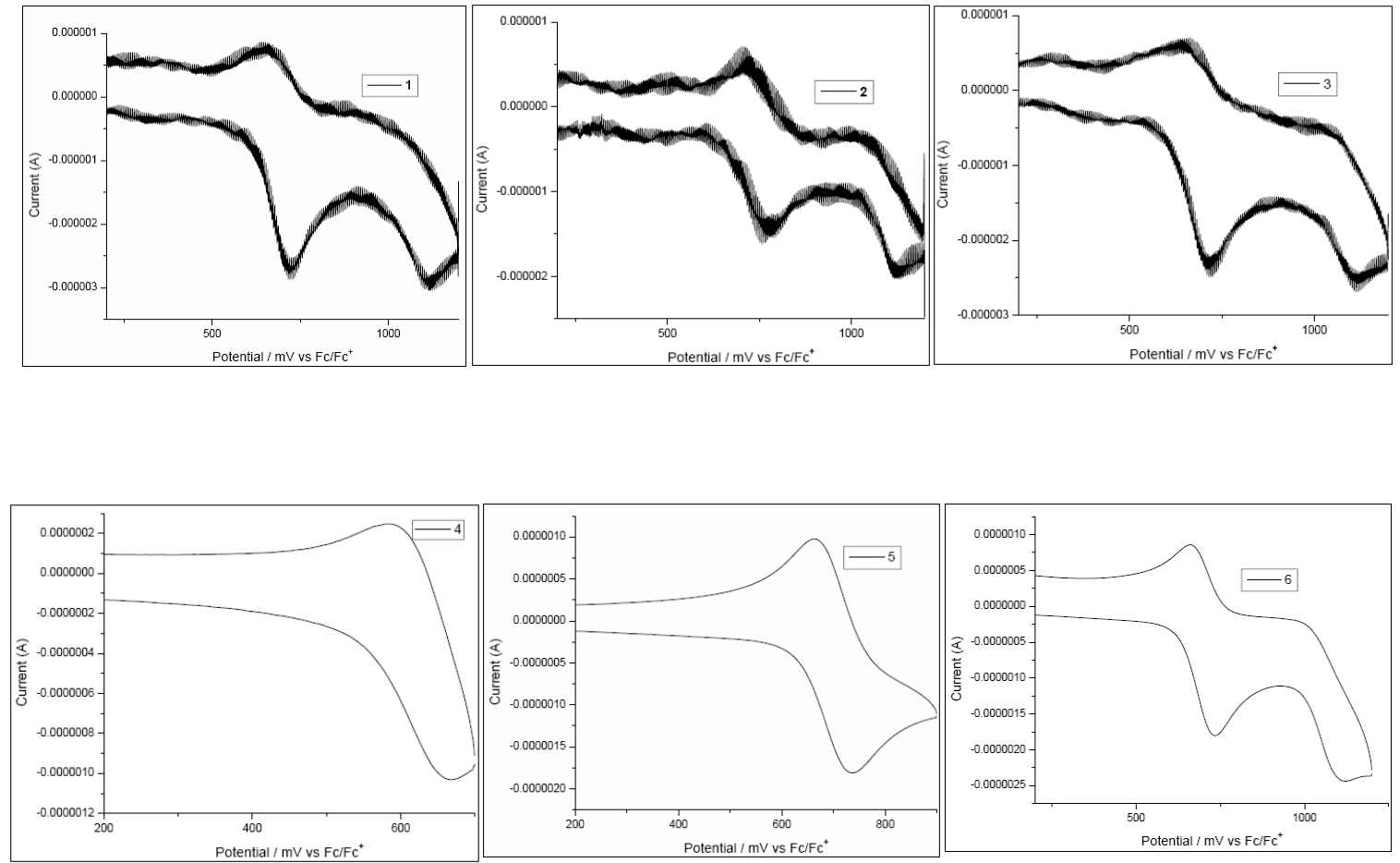
Figure S3. Fluorescence spectra of 1-6 in different solvents
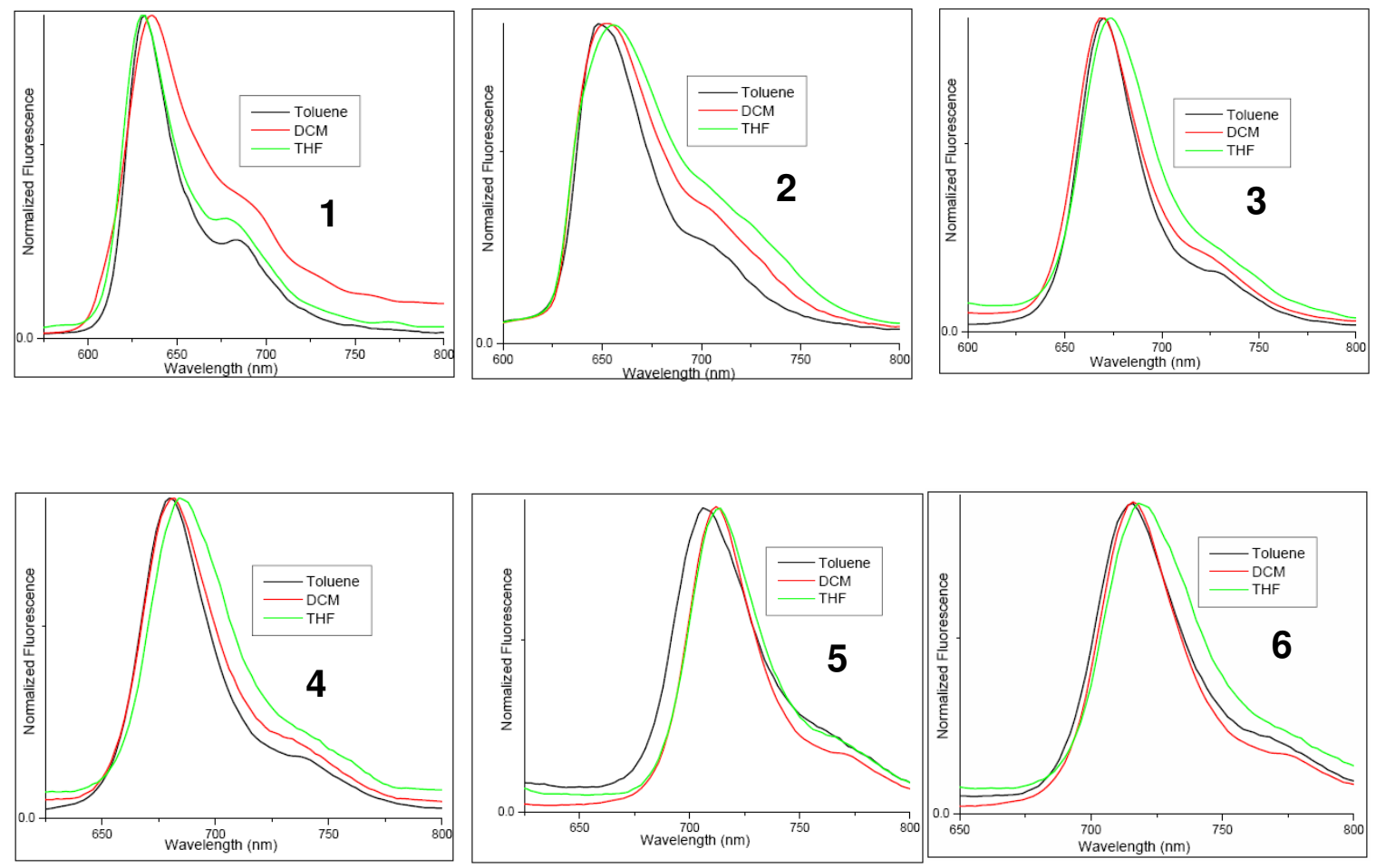

Table S1. Quantum yield of fluorescence $\left(\Phi_{F}\right)$ values of 1-6 recorded in different solvents

\begin{tabular}{|c|c|c|c|}
\hline \multirow{2}{*}{ Compound } & \multicolumn{3}{|c|}{$\Phi_{\mathrm{F}}$} \\
\cline { 2 - 4 } & Toluene & $\mathrm{CH}_{2} \mathrm{Cl}_{2}$ & THF \\
\hline $\mathbf{1}$ & 0.14 & 0.08 & 0.10 \\
\hline $\mathbf{2}$ & 0.10 & 0.09 & 0.09 \\
\hline $\mathbf{3}$ & 0.10 & 0.11 & 0.13 \\
\hline $\mathbf{4}$ & 0.10 & 0.09 & 0.11 \\
\hline $\mathbf{5}$ & 0.13 & 0.12 & 0.08 \\
\hline $\mathbf{6}$ & 0.11 & 0.11 & 0.12 \\
\hline
\end{tabular}



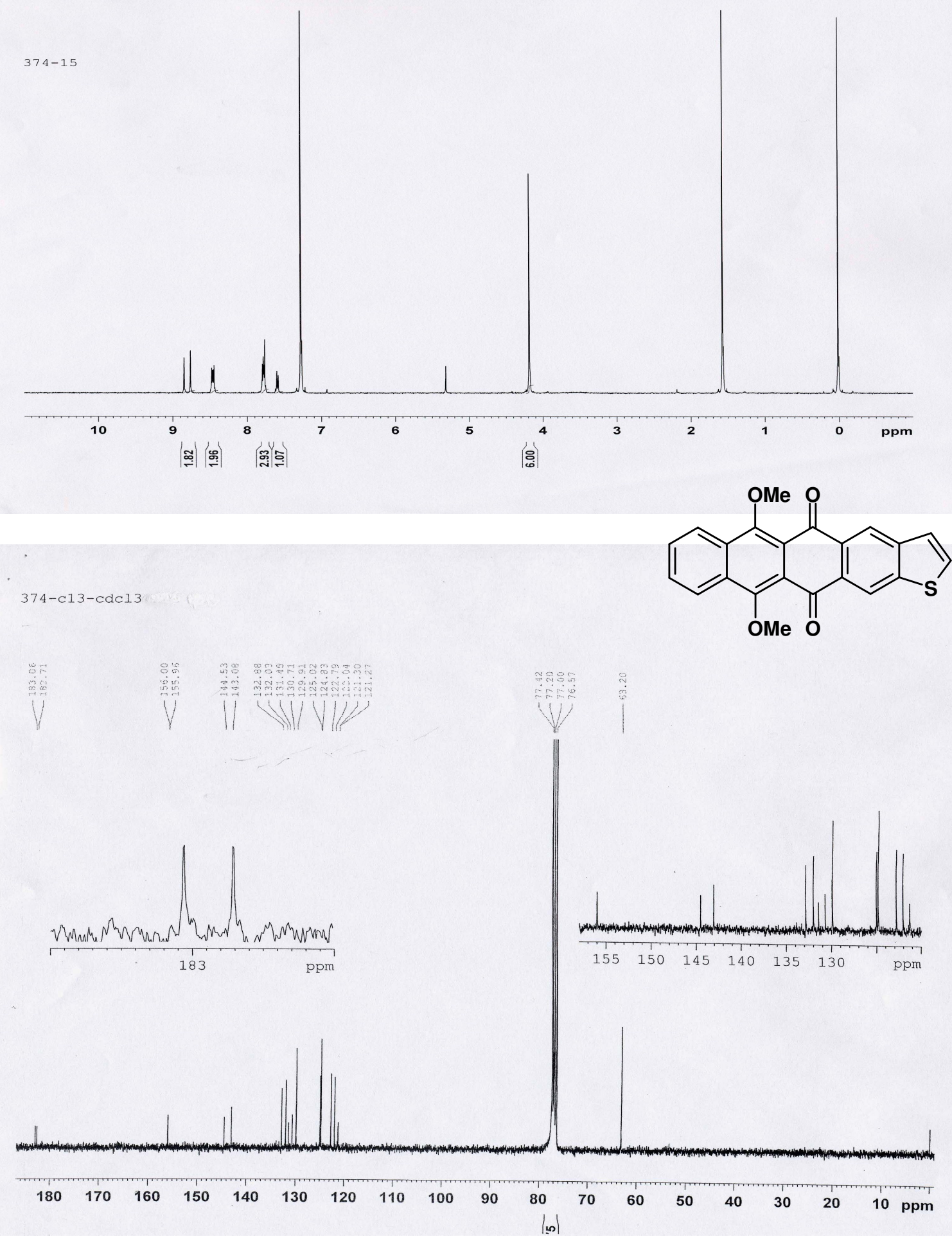

Figure S4. ${ }^{1} \mathrm{H}$ and ${ }^{13} \mathrm{C}$ NMR spectra of $\mathbf{1 1}$. 

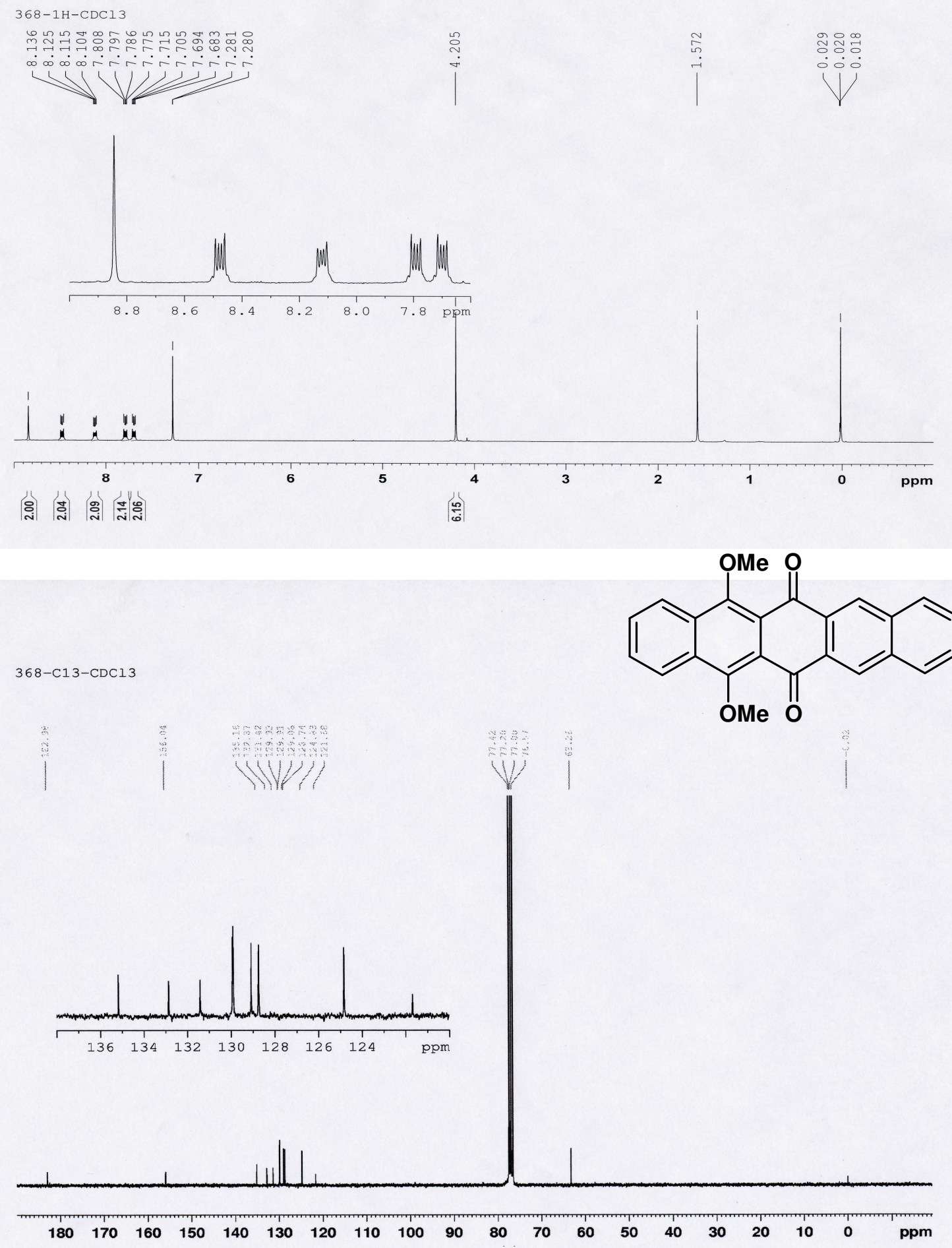

Figure S5. ${ }^{1} \mathrm{H}$ and ${ }^{13} \mathrm{C}$ NMR spectra of $\mathbf{1 2}$. 


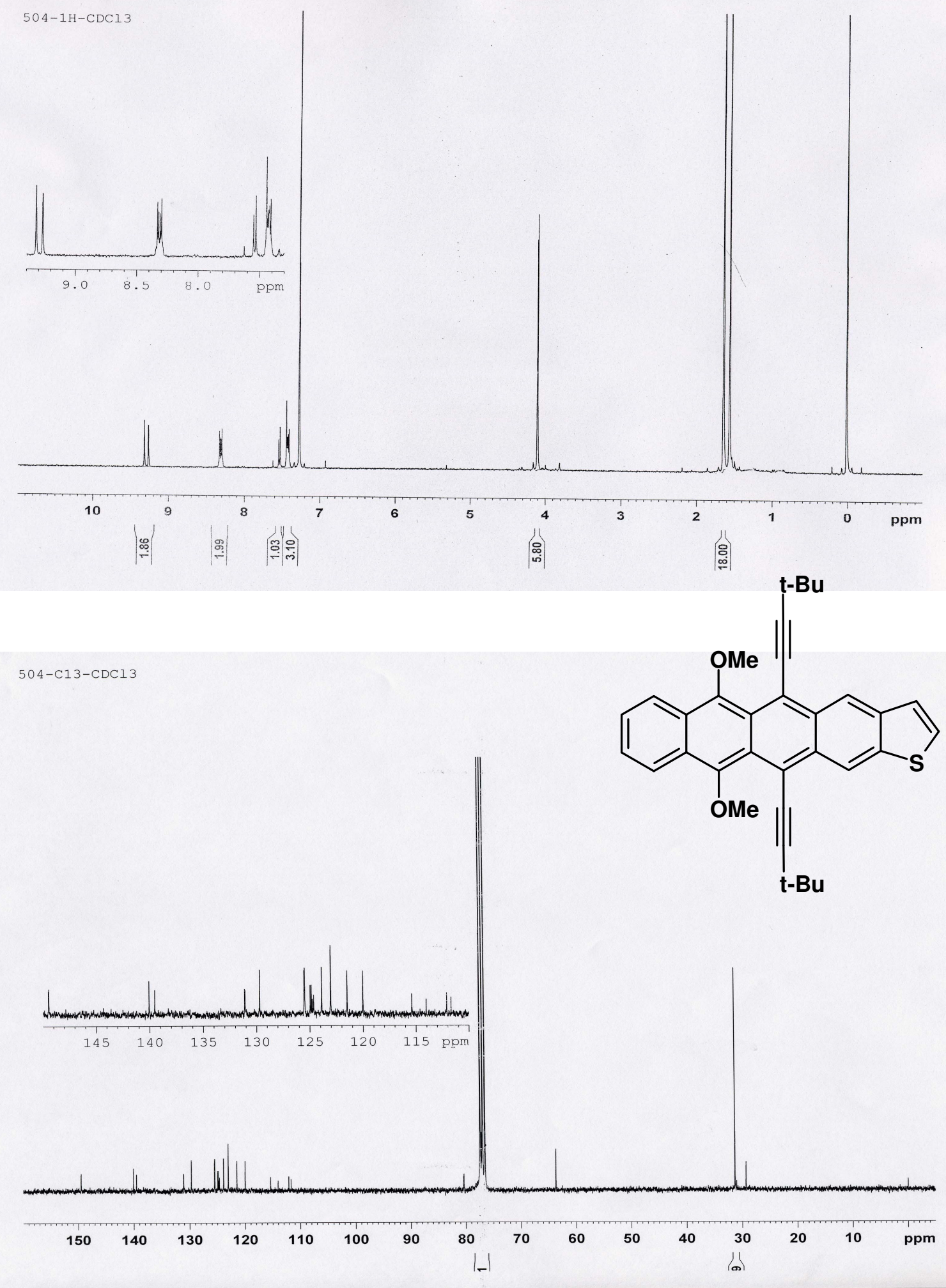

Figure S6. ${ }^{1} \mathrm{H}$ and ${ }^{13} \mathrm{C}$ NMR spectra of $\mathbf{1}$. 

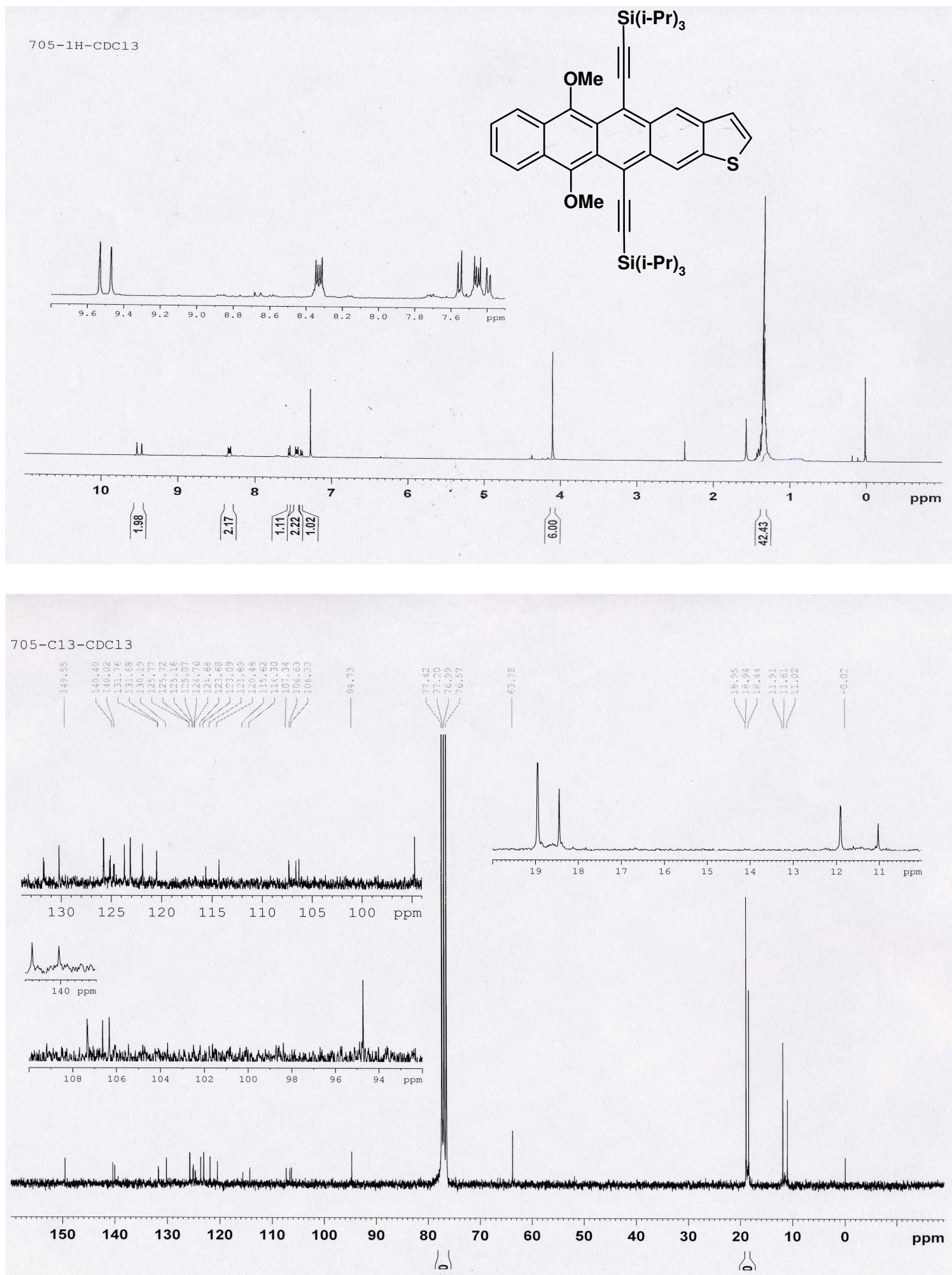

Figure S7. ${ }^{1} \mathrm{H}$ and ${ }^{13} \mathrm{C}$ NMR spectra of 2 . 

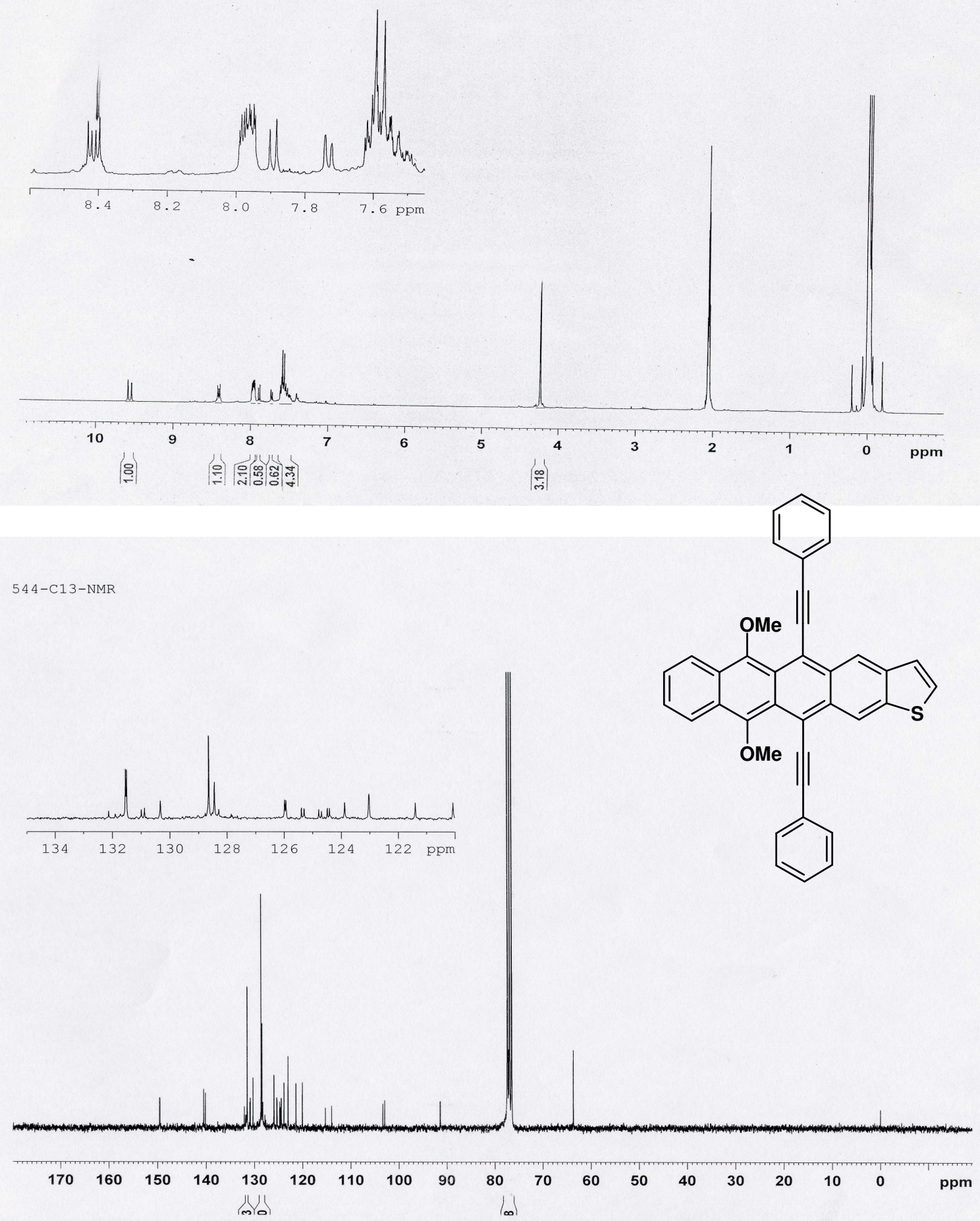

Figure S8. ${ }^{1} \mathrm{H}$ and ${ }^{13} \mathrm{C}$ NMR spectra of 3 . 

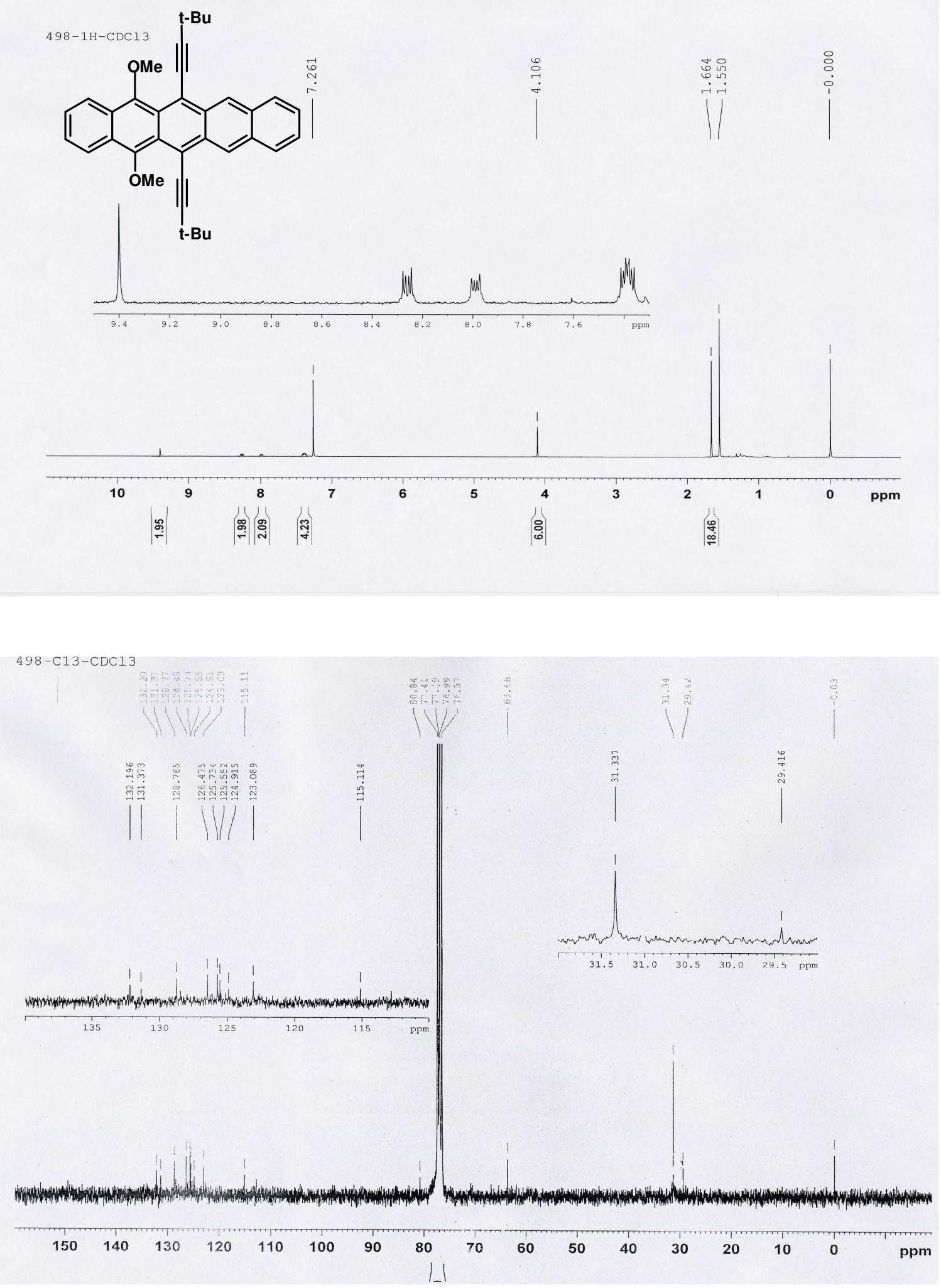

Figure S9. ${ }^{1} \mathrm{H}$ and ${ }^{13} \mathrm{C}$ NMR spectra of 4 . 
699-1H-CDC13
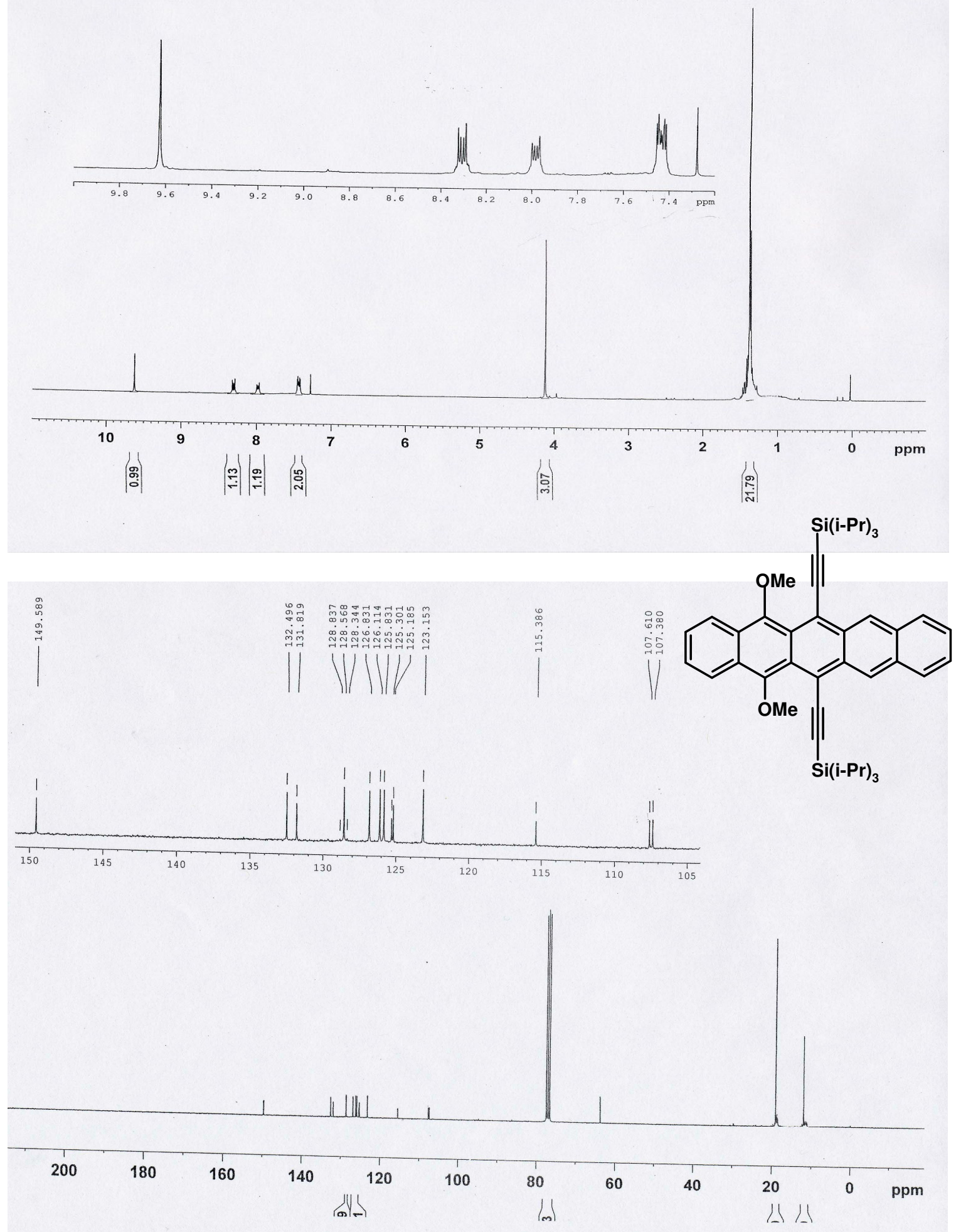

Figure S10. ${ }^{1} \mathrm{H}$ and ${ }^{13} \mathrm{C}$ NMR spectra of 5 . 

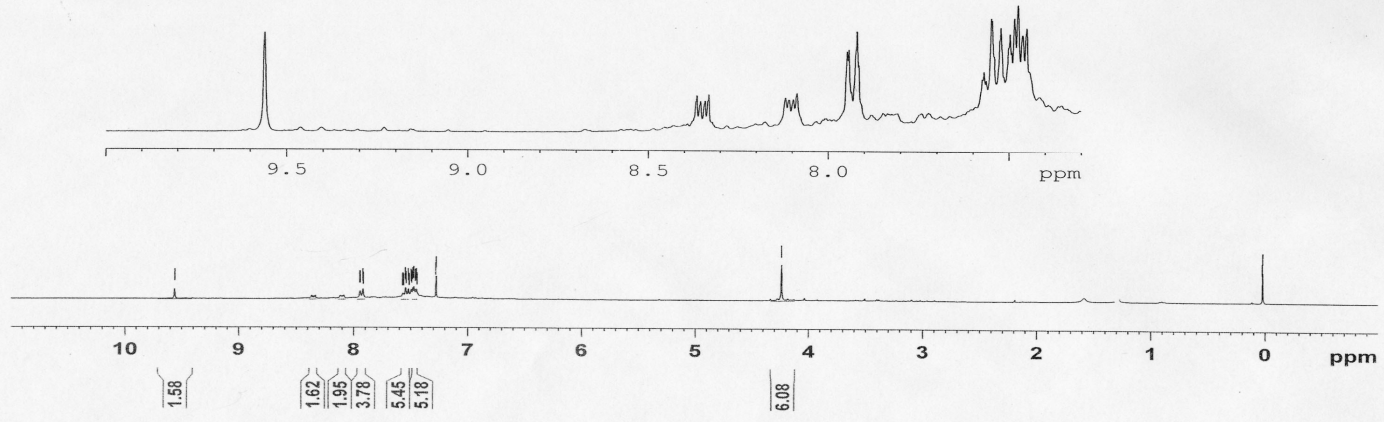

538-C13-CDC13

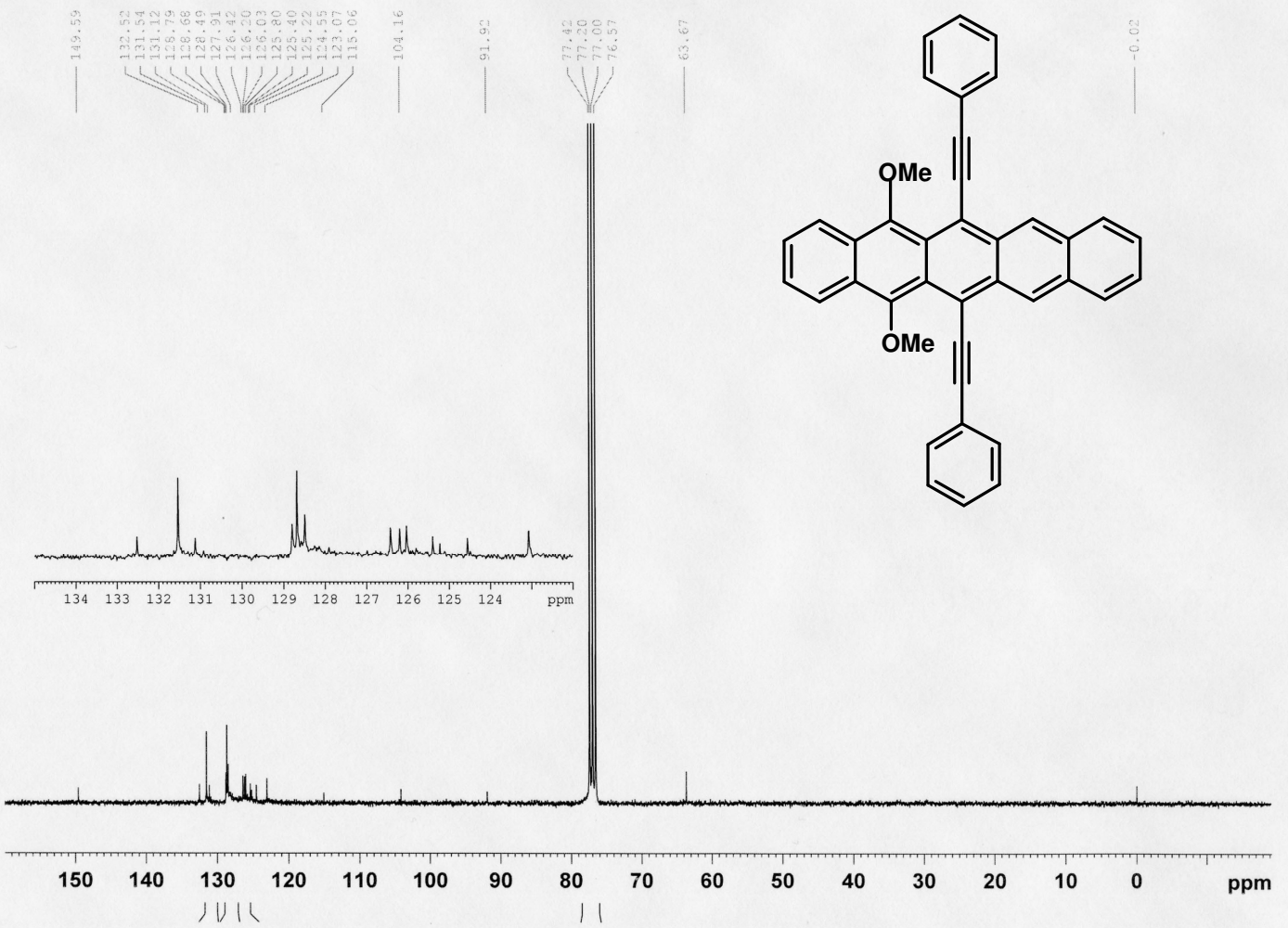

Figure S11. ${ }^{1} \mathrm{H}$ and ${ }^{13} \mathrm{C}$ NMR spectra of 6 . 


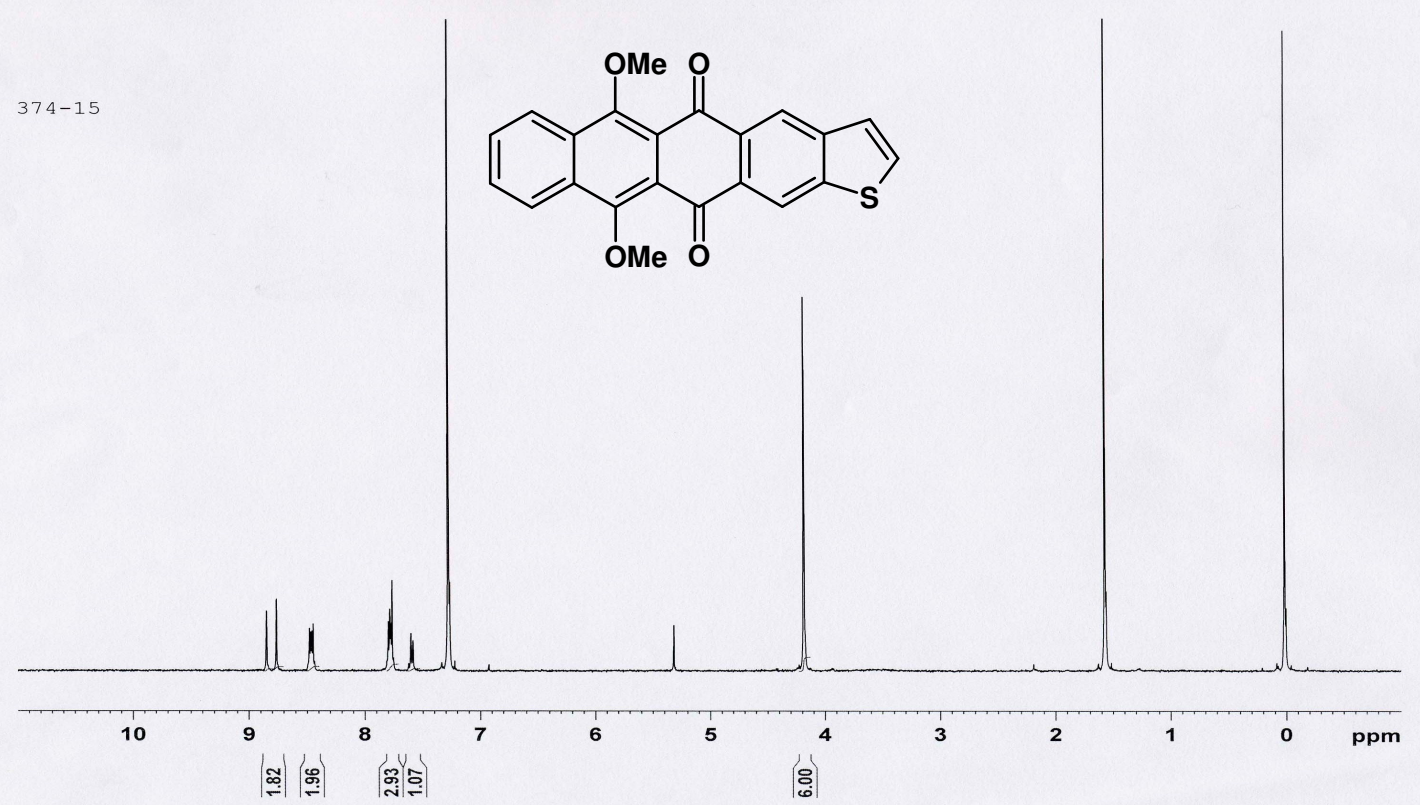

Figure S12. ${ }^{1} \mathrm{H}$ NMR spectrum of $\mathbf{1 1}$.

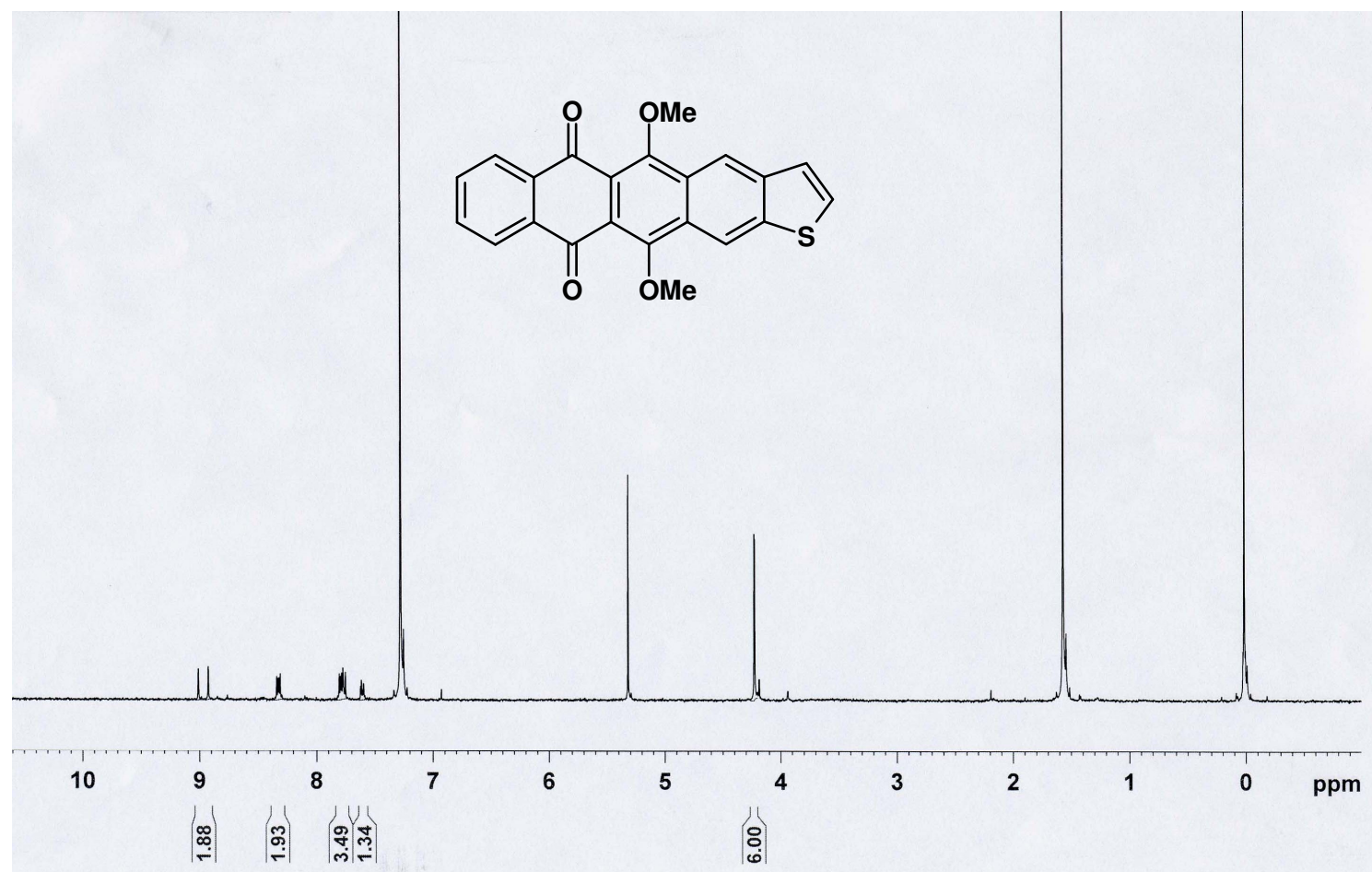

Figure S13. ${ }^{1}$ H NMR spectrum of 14 . 


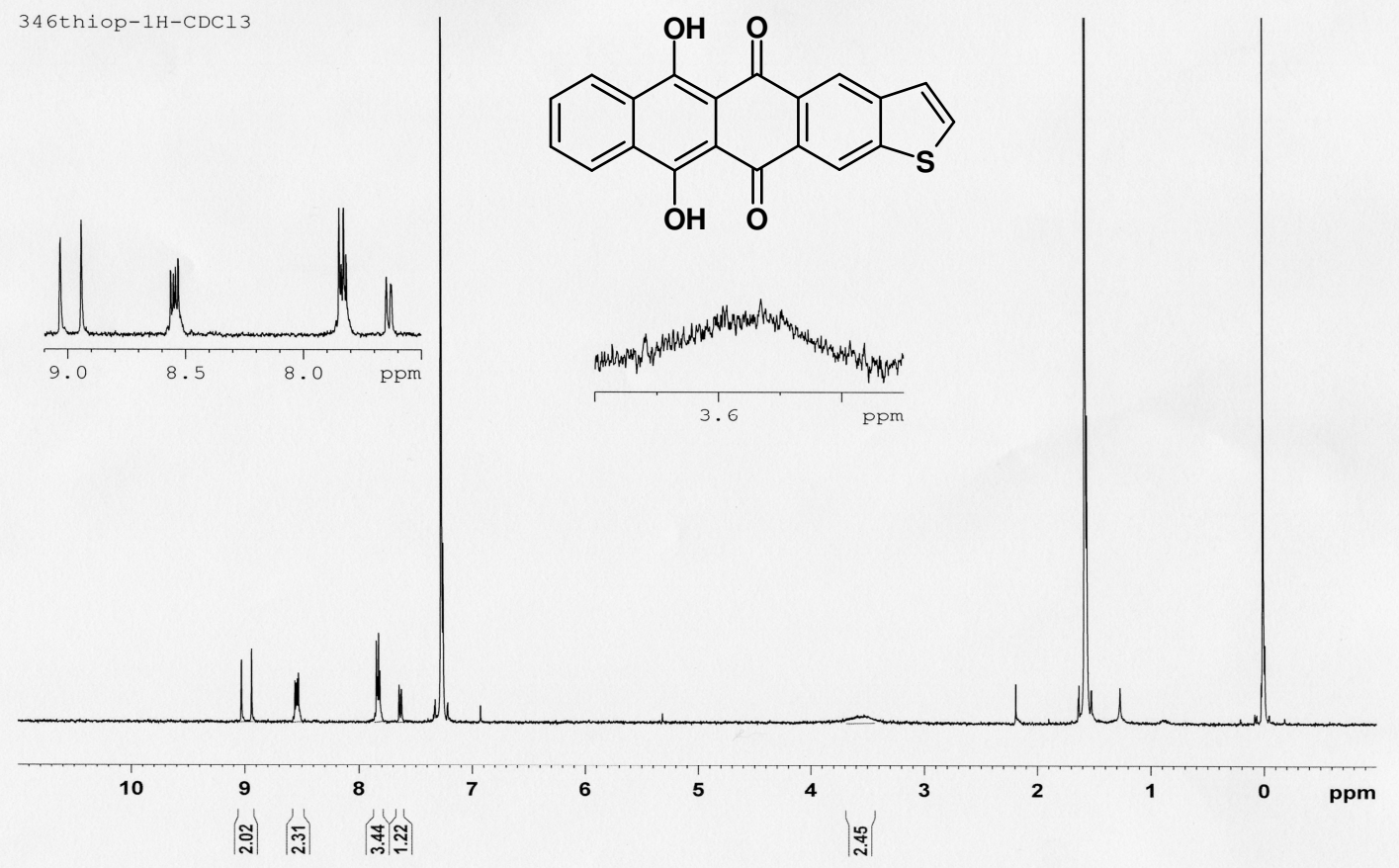

Figure S14. ${ }^{1} \mathrm{H}$ NMR spectrum of $\mathbf{1 3}$. 